\title{
The Thermodynamics of Tobacco-Water Interactions ${ }^{*}$
}

\author{
by \\ Joseph L. Banyasz, \\ Philip Morris U.S.A. \\ Research Center \\ P.O. Box 26583 \\ Richmond, VA 23261, USA
}

\section{SUMMARY}

An equation to describe the water sorption isotherm of tobacco is developed based on a model of the tobaccowater system as a mixture or solid solution comprised of water and water binding sites of many different kinds. It is assumed that free water has an activity coefficient of one. The result is an equation that predicts moisture content as a function of relative humidity given the numbers of each of the different kinds of sites and the associated water binding equilibrium constants. It is shown that this multi-site equation reduces to a one site equation if the different kinds of water binding sites are symmetrically distributed with regard to their affinity for water. The result is a two parameter, average site equation that fits water sorption data for tobacco over the range of $10-80 \%$ relative humidity.

The average site equation is identical to the equation derived by BRUNAUER, EMMETT and TELLER for binding to surface sites (1). The two models start from very different points of view but come to the same conclusion because they are ultimately based on thermodynamics which is indifferent as to the physical nature of the sites. Inferences as to the microscopic nature of water binding sites cannot be made from thermodynamic isotherm equations.

In order to describe the effects of water on the physical properties of tobacco the solution analogy is extended further. If tobacco is a mixture or solution of unhydrated sites, hydrated sites and free water, then the value of a physical property should be a function of the concentrations of those species and the associated partial molar values of the property. As the total moisture content changes the distribution of species will change and, in turn, change the properties. Applications of this rationale are presented for heat capacity, thermal diffusivity and the kinetics of the Browning reaction. The results demonstrate that the parameters derived from water sorption data play a more general role in the thermodynamics of the tobacco-water system.

\section{ZUSAMMENFASSUNG}

Eine Gleichung zur Beschreibung der isothermischen Wasseraufnahme von Tabak wurde entwickelt auf der Basis eines Modells des Tabak-Wasser-Systems als einer Mischung bzw. Feststofflösung, die aus Wasser und Wasserbindungsstellen verschiedener Arten besteht. Es wird angenommen, dass Wasser einen Aktivitätskoeffizienten von eins besitzt. Hieraus ergibt sich eine Gleichung, die entsprechend der Anzahl der verschiedenen Bindungsstellen unter zugehörigen Gleichgewichtskonstanten den Feuchtigkeitsgehalt als eine Funktion der relativen Feuchtigkeit berechnet. Es wird gezeigt, dass diese Gleichung mit mehreren Bindungsstellen auf die Beschreibung einer Bindungsstelle reduziert werden kann, wenn die verschiedenen Arten von Bindungsstellen 
bezüglich der Wasseraffinität symmetrisch verteilt sind. Das Ergebnis ist eine Gleichung mit zwei Parametern, die für Wasseraufnahmemengen im Tabak über einen relativen Luftfeuchtigkeitsbereich von $10-80 \%$ gültig ist.

Diese Gleichung ist identisch mit der, die von BRUNAUER, EMMETT und TELLER für die Bindung an Oberflächenstellen entwickelt wurde (1). Die Ausgangspunkte beider Modelle sind völlig unterschiedlich, kommen aber doch zum gleichen Ergebnis, da sie letztlich auf thermodynamischen Prinzipien basieren, für die die physikalische Natur der Bindungsstellen unerheblich ist. Schlussfolgerungen zur mikroskopischen Natur der Wasserbindungsstellen können aus thermodynamischen Gleichungen nicht gezogen werden.

Um die Auswirkungen von Wasser auf die physikalischen Eigenschaften von Tabak zu beschreiben, wird die Lösungsanalogie weiter entwickelt. Wenn Tabak aus einer Mischung bzw. Lösung von unhydratisierten Stellen, hydratisierten Stellen und freiem Wasser besteht, dann müßte der Wert einer physikalischen Eigenschaft die Funktion der Konzentration dieser Spezies und der entsprechenden Teilmolarwerte sein. In dem Masse, wie sich der Gesamtfeuchtigkeitsgehalt ändert, ändert sich auch die Verteilung der Spezies, und demzufolge ändern sich auch die Eigenschaften. Anwendungen dieser Methode werden für Wärmekapazität, Temperaturdiffusionsgrad und die Kinetik der Bräunungsreaktion gezeigt. Die Ergebnisse zeigen, dass die aus Wasseraufnahmedaten gewonnenen Parameter eine allgemeine Rolle in den thermodynamischen Eigenschaften des Tabak-Wassersystems spielen.

\section{RESUME}

Une équation visant à décrire l'isotherme d'absorption d'eau par le tabac est mise au point sur la base d'un modèle du système tabac-eau en tant que mélange ou solution solide comprenant de l'eau et des sites de fixation de l'eau de différents types. On fait l'hypothèse que l'eau libre a un coefficient d'activité de 1 . Il en résulte une équation qui prédit le taux d'humidité en fonction de l'humidité relative compte tenu des numéros de chacun des différents types de site et des constantes associées d'équilibre de fixation d'eau. Il est démontré que cette équation à plusieurs sites se réduit à une équation d'un site si les différents types de sites de fixation d'eau sont répartis normalement en ce qui concerne leur affinité pour l'eau. Il en résulte une équation de site moyen à deux paramètres compatible avec les données de l'absorption hydrique du tabac sur la plage de 10 à $80 \%$ d'humidité relative. L'équation de site moyen est identique à l'équation obtenue par BRUNAUER, EMMETT et TELLER pour fixation aux sites de surface (1). Les deux modèles partent de points de vue très différents mais aboutissent à la même conclusion parce qu'ils sont, en dernière analyse, basés sur une thermodynamique qui est indifférente à la nature physique des sites. Aucune déduction quant à la nature microscopique des sites de fixation d'eau ne peut être tirée des équations isothermes thermodynamiques.

L'analogie de la solution est développée afin de décrire les effets de l'eau sur les propriétés physiques du tabac. Si le tabac est un mélange ou une solution de sites non hydratés, de sites hydratés et d'eau libre, la valeur d'une propriété physique doit alors être fonction des concentrations de ces espèces et des valeurs molaires partielles associées de la propriété. A mesure que la teneur totale en eau change, la répartition des espèces changera et, à son tour, changera les propriétés. Les applications de ce raisonnement sont présentées pour la capacité thermique, la diffusion thermique et la cinétique de la réaction de Browning. Les résultats démontrent que les paramètres tirés des données de l'absorption d'eau jouent un rôle plus général dans la thermodynamique du système tabac-eau.

\section{INTRODUCTION}

Tobacco is a complex heterogeneous material comprised of a large variety of biopolymers in which are embedded a multitude of lower molecular weight compounds including inorganic salts, sugars and carboxylic acids. Water strongly interacts with and penetrates the tobacco matrix binding to specific sites on the polymers and dissolving some of the low molecular weight components even at moderate relative humidities.

HAILWOOD and HORROBIN, working on water sorption by textile fibers, treated the substrate-water system as a mixture of unhydrated sites, hydrated sites and unbound water (2). The concept of a mixture or solution seems particularly appropriate for tobacco. However, HAILWOOD and HORROBIN also assumed the sites are indistinguishable. The same assumption cannot, a priori, be made for tobacco.

The new model for water sorption presented here uses the solution formulation as a point of departure but starts with the assumption that many kinds of different water binding sites exist in tobacco. Water sorption models are generally restricted to a description of water binding to a substrate. The present analysis shows that the parameters which govern water sorption also determine the effect of water on the properties of tobacco such as heat capacity and thermal diffusivity. The model is general and is applicable to other agricultural materials. 


\section{EXPERIMENTAL}

Water sorption experiments

Duplicate 10 gram samples of tobacco were equilibrated for 48 hours at $25^{\circ} \mathrm{C}$ and the desired relative humidity in a Despatch Ecosphere 505 temperature/humidity chamber. The moisture contents were determined by drying the samples for three hours at $100{ }^{\circ} \mathrm{C}$ in a mechanical convection oven. All moisture contents are stated on a dry weight basis unless otherwise specified.

\section{Thermal diffusivity determinations}

The thermal diffusivity $D$ of tobacco samples was calculated from the corresponding thermal conductivity $K$, heat capacity $C_{P}$ and density $\varrho$ values via the relationship:

$$
D=\frac{K}{C_{p} \rho} .
$$

The thermal conductivities of tobacco strip and reconstituted sheet samples were determined at $25{ }^{\circ} \mathrm{C}$ using a thermal conductivity tester described elsewhere (4). The heat capacities of the reconstituted tobacco samples were determined by differential scanning calorimetry. For the strip tobacco samples published values of the heat capacities were used (5). The density of bone dry tobacco was determined by helium pycnometry using a Quantachrome Penta-Pycnometer Model PP-6. The densities of the samples were then estimated from the bone dry value and their moisture contents.

The thermal diffusivity at $45{ }^{\circ} \mathrm{C}$ of an $18 \%$ solids cast leaf slurry was directly determined. A sample of the slurry was placed in a water jacketed cylindrical cell equipped with a thermocouple on the center line of the cylinder. The sample was equilibrated to $40^{\circ} \mathrm{C}$. The jacket temperature was then raised to $50^{\circ} \mathrm{C}$ and the time course of the temperature change on the centerline monitored. After the slurry had equilibrated to $50^{\circ} \mathrm{C}$, the jacket temperature was lowered to $40^{\circ} \mathrm{C}$ and the resulting cooling curve was monitored. The thermal diffusivity, $D$, was extracted from the temperature data using standard heat transfer equations (3):

$$
\Phi=2 \sum\left(\exp \left(-\lambda_{n}^{2} D t / r^{2}\right)\right) /\left(\lambda_{n} J_{1}\left(\lambda_{n}\right)\right)
$$

where:

$$
\Phi=\left(T-T_{1}\right) /\left(T_{0}-T_{1}\right)
$$

and $T_{1}, T_{0}, T, t, r$ and $\lambda_{n}$ are the surface (i.e. jacket) temperature of the cylinder, the initial temperature on the center line, the temperature on the center line, the time, the radius of the cylinder and the roots of the zeroth order Bessel function, respectively. The series was truncated at seven terms. The heating and cooling curves yielded a value of $(1.36 \pm 0.03) \times 10^{-7} \mathrm{~m}^{2} / \mathrm{s}$ for the thermal diffusivity. The thermal diffusivity of the slurry was corrected to $25^{\circ} \mathrm{C}$ using the temperature dependence of the thermal diffusivity for water as calculated from the CRC Handbook (6).

\section{Heat treatment of tobacco}

Samples of tobacco at the desired moisture content were sealed into containers which were then placed in a mechanical convection oven at $90^{\circ} \mathrm{C}$ for 48 hours. The samples were then cooled and equilibrated to $60 \% \mathrm{RH}$. The treatment induces a number of changes in tobacco including darkening of color, loss of reducing sugars, reduction of equilibrium moisture content and increases in filling power as well as friability. Filling power increase was used as the measure of the extent of the changes. The filling power increase was defined as the filling power of the treated tobacco equilibrated to $60 \% \mathrm{RH}$ and $24^{\circ} \mathrm{C}$ less the filling power of the control at the same moisture content as the test material.

Filling power or cylinder volume (CV) measurements were carried out with a Borgwaldt Densimeter DD-60 instrument. Twenty gram samples of tobacco were used per determination. The CV value was calculated, in terms of $\mathrm{cm}^{3} / \mathrm{g}$, from the cross-sectional area and height of the cylindrical tobacco bed after 30 seconds of compression under a force of two kilograms. The procedure was carried out as quickly as possible to minimize changes in the moisture content of the tobacco. The moisture content of the sample was determined after the CV test. All determinations were carried out in duplicate.

\section{DEVELOPMENT OF THE ISOTHERM MODEL}

The model makes three basic assumptions:

1. It is assumed that water binds to discrete sites in the substrate. This is common to all isotherm models.

2. It is assumed that the tobacco-water system is a mixture, comprised of unhydrated sites, bound water and unbound or free water, to which the laws of simple solution thermodynamics apply.

3. All deviations from ideality are due to water binding by tobacco sites. Water vapor pressure lowering is due entirely to the reduction of the concentration of free water by biding to sites.

The first two assumptions are identical to those of the Hailwood-Horrobin model. The third derives from semiideal solution theory which is discussed in a subsequent section. 
Since tobacco is comprised of many different constituents capable of interacting with water, it follows that there should be a corresponding number of kinds of sites designated as $S_{1}, S_{2} \ldots S_{n}$. For each type of site the water binding equilibrium is given by:

$$
S_{i}+W \rightleftharpoons W S_{i}
$$

The associated equilibrium constants are defined in terms of mole fractions:

$$
K_{i}=\frac{X_{W S_{i}}}{X_{W} X_{S_{i}}}
$$

With each there is an associated mole balance given by:

$$
S_{i}^{0}=n_{S_{i}}+n_{W S_{i}}
$$

where the $n$ 's are mole numbers per gram of bone dry tobacco. The overall total mole number of sites per gram bone dry tobacco is then given by:

$$
S^{0}=\sum_{i=1}^{n} S_{i}^{0}
$$

The summation in equation [4] is over all sites both hydrated and unhydrated. It follows that the total number of moles of all species in the system $N^{0}$ is given by:

$$
N^{\circ}=S^{0}+n_{W}
$$

As stated above, it is assumed that the activity coefficient of free water is unity. It then follows from Raoult's law that:

$$
X_{W} \equiv \frac{n_{W}}{N^{\ominus}}=\frac{n_{W}}{s^{0}+n_{W}}=b
$$

where $b$ stands for the decimal relative humidity. Equation [6] may be rearranged to obtain the number of moles of free water per gram bone dry tobacco as a function of relative humidity:

$$
n_{W}=\frac{b}{1-b} s^{0}
$$

It should be noted that the right hand side of equation [7] goes to infinity as the relative humidity approaches $100 \%$. Nevertheless, as will be shown below, the equation works well for tobacco up to a relative humidity of at least $80 \%$.

It now remains to determine the concentration of bound water as a function of $h$. Substitution of $b$ for and rearrangement of equation [2] yields:

$$
n_{W S_{i}}=K_{i} n_{S_{i}} h
$$

Substitution of equation [8] into mole balance equation [3] and rearrangement yields:

$$
n_{S_{i}}=\frac{S_{i}^{0}}{1+K_{i} h}
$$

Substitution of equation [9] into equation [8] yields:

$$
n_{W S_{i}}=\frac{K_{i} S_{i}^{0} h}{1+K_{i} h}
$$

The total bound water is obtained by summing equation [10] over all site types:

$$
n_{W S}=\sum_{i=1}^{n} \frac{K_{i} S_{i}^{0} h}{1+K_{i} h}
$$

The total water held by the tobacco $m$, in units of grams per gram dry tobacco, follows from the addition of equations [7] and [11] and multiplication by 18, the molecular weight of water:

$$
m=18\left(\frac{b}{1-b} S^{0}+\sum_{i=1}^{n} \frac{K_{i} S_{i}^{0} h}{1+K_{i} h}\right)
$$

Equation [12] is an exact isotherm equation for a substrate with many kinds of sites. Unfortunately it is also virtually intractable. It not only potentially contains a large number of unknowns but is also nonlinear.

However, as will be shown below, tobacco sorption data fit very nicely to an isotherm equation involving only one kind of site. The question thus becomes how to reconcile equation [12] with a simple one site model. The reconciliation can be accomplished by making the assumption that the sites in tobacco are normally distributed with regard to the water binding equilibrium constants. In this case, the $K_{i}$ 's in equation [12], to a very good approximation, can be replaced by the distribution average $K$. Equation [12] then reduces to:

$$
m=18 S^{0}\left(\frac{h}{1-b}+\frac{K h}{1+K h}\right)
$$

The equivalence of equations [12] and [13] is demonstrated by computation. Figure 1 shows a normal distribution of eight sites. The average value for the 


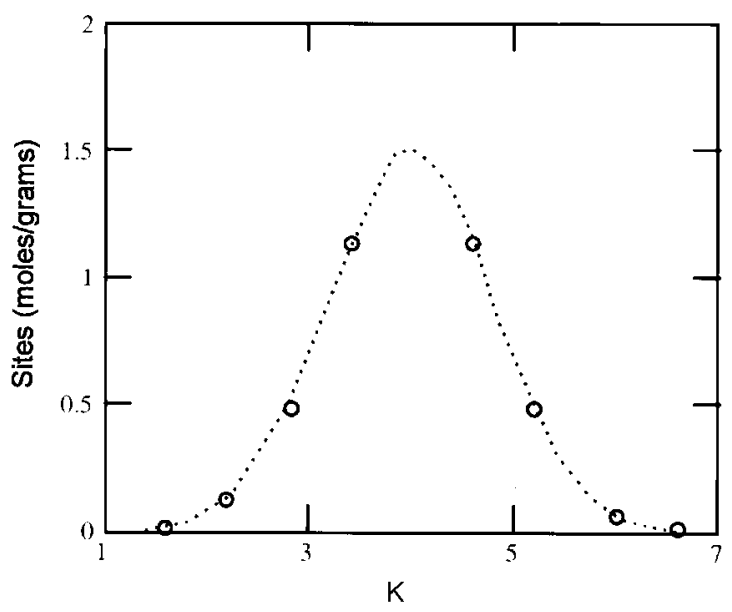

Figure 1.

\section{Hypothetical normal distribution of sites used to evaluate equation [14].}

binding constant $K$ is 4 and the overall number of sites is $3.4 \times 10^{-3}$ moles. These values were substituted into equation [13] to calculate $m$ as a function $h$. The eight sets of values for $K_{i}$ and $S_{i}^{0}$ shown in the distribution were then substituted into equation [12] to also calculate $m$ as a function of $h$. The comparison of the two calculations is shown in Table 1. The difference between them is in the fourth decimal place ranging from 3 to $6 \times 10^{-4}$. For all practical purposes, the two results are identical.

The requirement with respect to distributions is symmetry. The approximation works as well for symmetrical, non-normal distributions. The approximation generally improves as the distribution narrows.

The conclusion is that tobacco sorption data conform to a one site isotherm equation with the stipulation that $S^{0}$ is a summation over distinguishable subsets of sites and that $K$ pertains to an average site.

Equation [13] is equivalent to the Brunauer-EmmettTeller (BET) equation (1). This is apparent when equation [13] is transformed to the more familiar form:

$$
\frac{h}{m(1-b)}=A+B h
$$

where: $\quad A=\frac{1}{185^{\circ}} \times \frac{1}{K+1}$

and: $\quad B=\frac{1}{185^{\circ}} \times \frac{K}{K+1}$.

The BET equation (1) was developed to describe adsorption to surfaces, a model quite different from the present one. The tobacco model represented by equation [13] and the BET equation lead to the same end result because they reduce to the same thermodynamic formulation based on two general assumptions:

1. Bound water is in equilibrium with free water. In the present model this assumption is explicit. The BET model assumes exchange of water between layers including the monolayer.

2. Free water is identical in its properties to bulk water. The present model assumes an activity coefficient of one for free water. The BET model assumes that the heat of vaporization from all layers beyond the monolayer is equal to the heat of vaporization of pure water.

Thermodynamic formulations, by their very nature, are not sensitive to the microscopic details of the sites. Consequently, the equation can only yield the value of the water binding equilibrium constant and the number of sites. Further inferences as to the nature of the sites must come from other sources of information. Originally the BET equation was derived for the adsorption of permanent gases onto materials such as catalysts and carbon. Binding to surface sites is the only reasonable possibility for those systems. The tobacco-water system presents a greater range of possibilities.

\section{WATER SORPTION ISOTHERMS}

Equation [14] was applied to sorption data over the range $40-80 \% \mathrm{RH}$ for a series of tobacco samples including bright, Burley, an uncased blend and a reconstituted tobacco. The results are summarized in Table 2. Excellent fits were obtained in all cases as indicated by the $R$ values. This is in agreement with previous demonstrations of the applicability of the BET equation to water sorption by tobacco $(7,8)$. The Burley tobacco exhibited a water binding constant value of 7 versus 3.1 for bright. The

Table 1.

Calculated isotherms.

\begin{tabular}{c|c|c|c}
\hline $\mathrm{h}$ & Equation 12 & Equation 13 & Difference $\times 10^{4}$ \\
\hline 0.1 & 0.02433 & 0.02463 & 3.0 \\
0.2 & 0.04260 & 0.04310 & 5.0 \\
0.3 & 0.05986 & 0.06045 & 6.0 \\
0.4 & 0.07894 & 0.07957 & 6.3 \\
0.5 & 0.1028 & 0.1034 & 6.4 \\
0.6 & 0.1363 & 0.1369 & 6.3 \\
0.7 & 0.1899 & 0.1906 & 6.2 \\
0.8 & 0.2950 & 0.2955 & 6 \\
\hline
\end{tabular}


Table 2.

Isotherm parameters.

\begin{tabular}{l|c|c|c|c}
\hline Sample & $\mathrm{K}$ & $\mathrm{S}^{0} \times 10^{3}$ & $\begin{array}{c}\text { Total bound } \\
\text { water }\end{array}$ & $\mathrm{R}$ \\
\hline Bright & 3.1 & 3.76 & 0.07 & 0.998 \\
Blend & 4.8 & 3.72 & 0.07 & 0.998 \\
Burley & 7.0 & 3.25 & 0.06 & 0.993 \\
Reconstitute & 5.0 & 4.03 & 0.07 & 0.993 \\
\hline
\end{tabular}

greater affinity of Burley for water is explained by the fact that it contains lower levels of solubles particularly sugars. This shifts the average of the binding constant distribution toward the more tightly binding polymer sites. The blend and the reconstituted sample contain both bright and Burley and, consequently, yield intermediate values. The reconstituted sample yields the largest value for $S^{0}$ because it is the only sample to contain humectant. The total bound water contents ranged from 6 to $7 \%$. Calculations indicate 4 to $5 \%$ bound water at $60 \% \mathrm{RH}$.

The bright tobacco isotherm is shown in Figure 2. The relative error between prediction and experimental value was $1 \%$ or less for all four tobaccos. BARNES et al. (9) quote $14.8 \times 10^{-16} \mathrm{~cm}^{2}$ as the surface area of an adsorbed water molecule. Based on the total water binding capacities in Table 2, one can calculate a hydrophilic surface area of $290-330 \mathrm{~m}^{2} / \mathrm{g}$ for tobacco. JADRAQUE and MENDIOLA obtained values of $64-248 \mathrm{~m}^{2} / \mathrm{g}$ using $10.5 \times 10^{-16} \mathrm{~cm}^{2}$ as the surface area of an adsorbed water molecule (8). These are very large values approaching those of activated carbon. BRUNAUER, EMMETT and TELLER estimated surface areas of 650 to $900 \mathrm{~m}^{2} / \mathrm{g}$ for carbon based on the adsorption of various permanent gases (1).

CHANG and JOHNSON (10) determined values of $0.19-0.45 \mathrm{~m}^{2} / \mathrm{g}$ for the krypton sorption surface of Coker 319 tobacco. The authors indicate that the outgassing of the tobacco samples required heating at $75^{\circ} \mathrm{C}$ for periods of about ten hours. This will result in some shrinkage leading to a reduction in surface area. However, it is improbable that the shrinkage would be large enough to reduce the surface area by the two to three orders required to reconcile the krypton and water surface areas. Furthermore, the reduction in specific volume accompanying such a large decrease in surface area would lead to unacceptably high densities. It appears reasonable to assume that the krypton surface approximates the geometric surface area of tobacco within an order of magnitude at least. The hydrophilic surface area of tobacco is about three orders of magnitude larger.
JADRAQUE and MENDIOLA (8) point out that the form of the BET equation represented by equation [14] yields reliable estimates of surface area only when the interaction between the surface and the adsorbed species is stronger than the interactions between the molecules of the adsorbed species. This requires that $K>>1$ or that the heat of desorption from the surface be larger than the heat of vaporization of the liquid (11). In the alternative case only an "apparent" value of the surface area is obtained (8). The first condition suggests that $K$ should have a value of at least 10. The experimental values for $K$ shown in Table 2 range from 3 to 7 . The values of the isosteric heat of desorption of water from tobacco range from $15.6 \mathrm{kcal} / \mathrm{mole}$ at $1 \%$ moisture to $10.9 \mathrm{kcal} / \mathrm{mole}$ at $20 \%$ moisture $(12,13)$. The heat of vaporization of water at $25^{\circ} \mathrm{C}$ is $10.5 \mathrm{kcal} / \mathrm{mole}$. The tobacco-water interaction is stronger than the water-water interaction at very low moisture contents but decreases rapidly as moisture content increases. The tobacco isotherm appears to be an intermediate case which raises some question as to the meaning of the calculated surface areas. Nevertheless, it seems difficult to explain an error of three orders of magnitude on this basis.

The very large water surface area appears consistent with a solution model where it represents virtually entirely an internal surface resulting from the interactions between water and the tobacco constituents. PAULING demonstrated that the hydrophilic surface of proteins, as determined from BET isotherms, corresponds to the binding of one water molecule per polar group (14). There is no reason to expect that tobacco should behave differently. Most polar groups in tobacco are expected to be internal rather than on the surface.

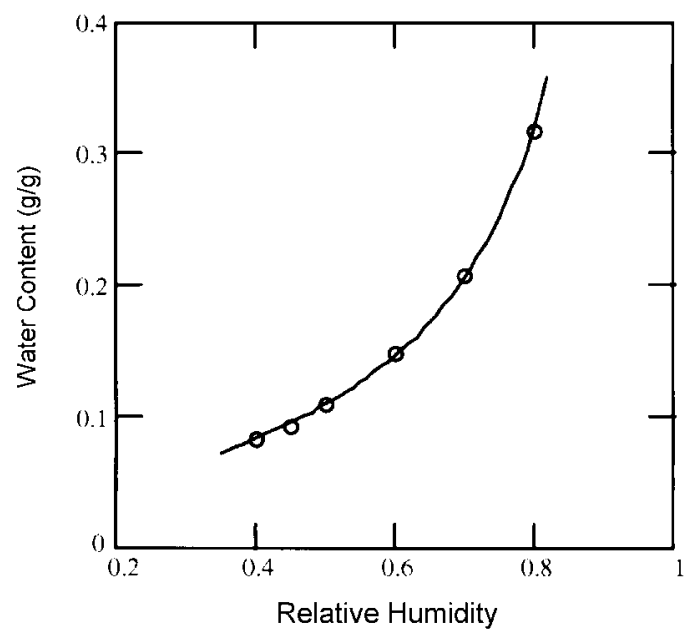

Figure 2.

Water sorption isotherm for bright tobacco. The line through the data was calculated using equation [13]. 


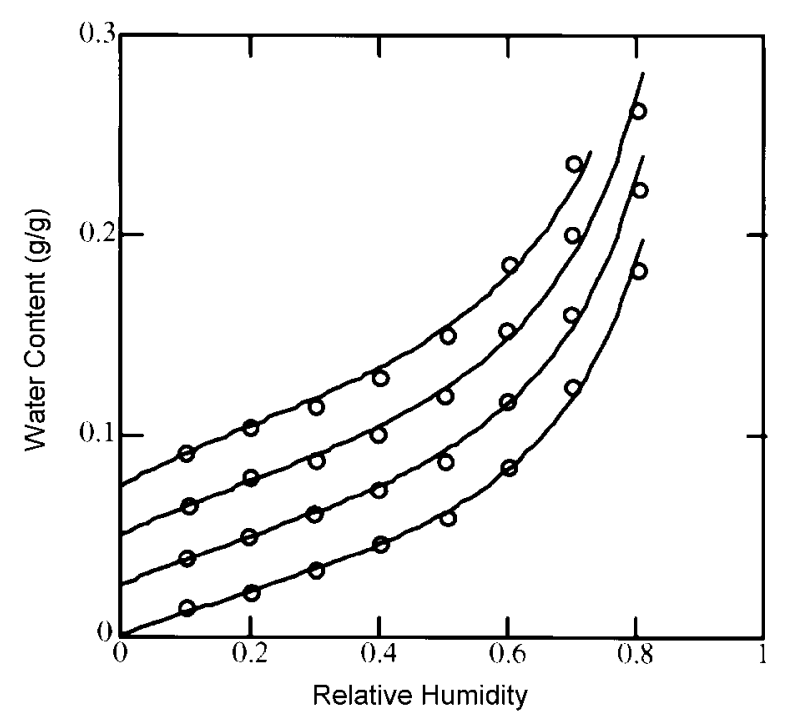

Figure 3.

Water sorption isotherms for bright tobacco as a function of temperature. The data points are from reference 12 and the lines were calculated using equation [13]. The experimental temperatures from top to bottom are $27,38,49$ and $60^{\circ} \mathrm{C}$. The curves have been offset by 0.025 each in ascending order for clarity.

The experimental isotherms were limited at the dry end to an $\mathrm{RH}$ of $40 \%$ by the accuracy of the conditioning chamber. The applicability of equation [14] at low relative humidities was tested using water sorption data published by SAMFIELD and coworkers (13) for bright tobacco over the 10-80\% range at temperatures of 27 , 38,49 and $60^{\circ} \mathrm{C}$. The results are shown in Figure 3. The curves, in ascending order, have been offset by 0.025 for clarity. The relative errors for these fits were in the 2-4\% range. The isotherm at $27^{\circ} \mathrm{C}$ yields values of 2.7 and $2.8 \times 10^{-3}$ for $K$ and $S^{0}$. The $K$ value is in agreement with values shown in Table 2 while the $S^{0}$ value is considerably smaller. The discrepancy in $S^{0}$ is likely due to a difference in the method of water determination between this work and SAMFIELD and coworkers which could introduce a systematic difference between the data sets.

The isotherms of SAMFIELD and coworkers yield the temperature dependences of the isotherm parameters. The temperature dependence of the equilibrium constant yields a value of $-1.8 \mathrm{kcal} /$ mole for the hydration of the average site $\Delta H_{\text {byd }}$ via the van't Hoff isochore. The temperature dependence is shown in Figure 4.

The number of sites $S^{0}$ decreases with increasing temperature as shown in Figure 5. The reason for this is not obvious. Based on the assumption that the phenomenon is linearly related to some underlying reversible process describable by an equilibrium constant, one calculates an enthalpy, $\Delta H_{s}$, of $1.2 \mathrm{kcal} / \mathrm{mole}$. One can only speculate as to the nature of the process.

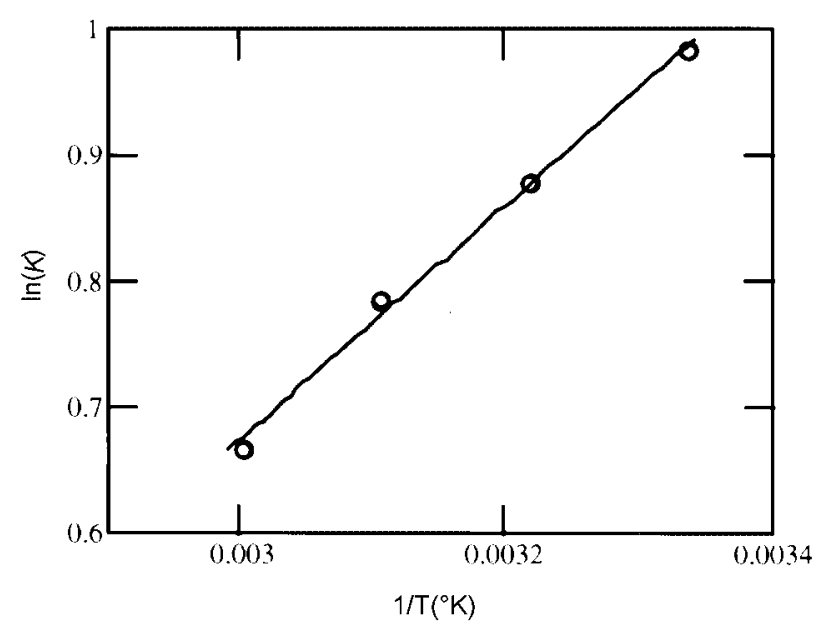

Figure 4.

Temperature dependence of the water binding equilibrium constant of bright tobacco. The values of the equilibrium constant were calculated as a function of temperature from the isotherms shown in Figure 3 using equation [14].

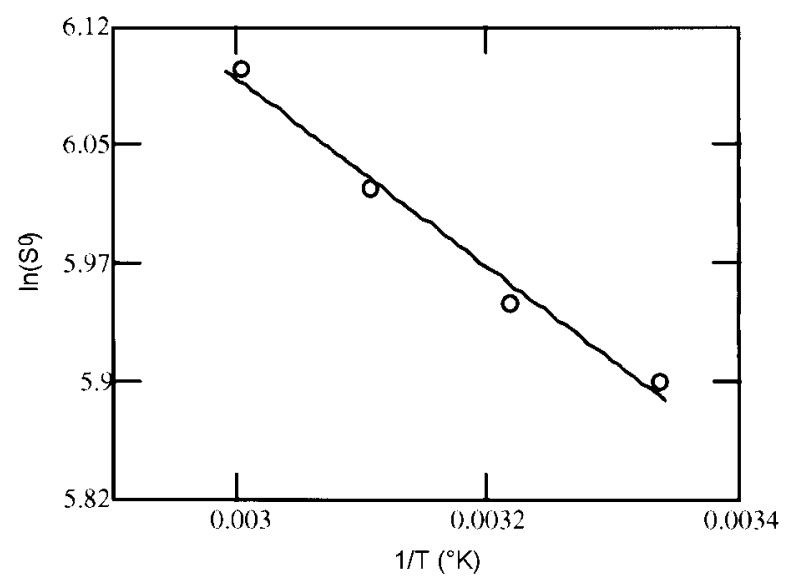

Figure 5.

Temperature dependence of the number of water binding sites in bright tobacco. The values were calculated as a function of temperature from the isotherms shown in Figure 3 using equation [14].

The thermodynamics of water binding can be obtained from the data of SAMFIELD and coworkers. A value of $-0.6 \mathrm{kcal}$ per mole is obtained for the standard Gibbs free energy of hydration $\Delta G_{b y d}$ at $25^{\circ} \mathrm{C}$ via the relationship:

$$
\Delta G_{\text {byd }}=-R T \ln K \text {. }
$$

The standard entropy of hydration may be calculated from: 


$$
\Delta S_{\text {byd }}=\frac{\Delta H_{b y d}-\Delta G_{b y d}}{T} .
$$

A value of $-4.0 \mathrm{cal} /$ degree mole is obtained for $\Delta S_{\text {byd }}$ at $25^{\circ} \mathrm{C}$. Since relative humidity rather than vapor pressure were used for water vapor concentration, this value refers to the binding of liquid water to tobacco. In comparison, the entropy of freezing for liquid water at $0^{\circ} \mathrm{C}$ is -5.3 $\mathrm{cal} /$ degree mole.

\section{SPECIES DISTRIBUTION AND PHYSICAL PROPERTIES}

In order to apply the model to the physical effects of water on tobacco, the solution analogy must be taken a step further. The properties of a solution are determined by the concentrations and properties of its constituents. In this context, the value of a tobacco physical property at any given moisture content should reflect the molar contributions and concentrations of unhydrated sites, hydrated sites and free water. As the total moisture content changes, so will the species distribution which will, in turn, alter the property.

The value $L$ of a physical property may be partitioned into contributions from the constituent species of a solution. For tobacco one may write:

$$
L=\Lambda_{W} X_{W}+\Lambda_{W S} X_{W S}+\Lambda_{S} X_{S}
$$

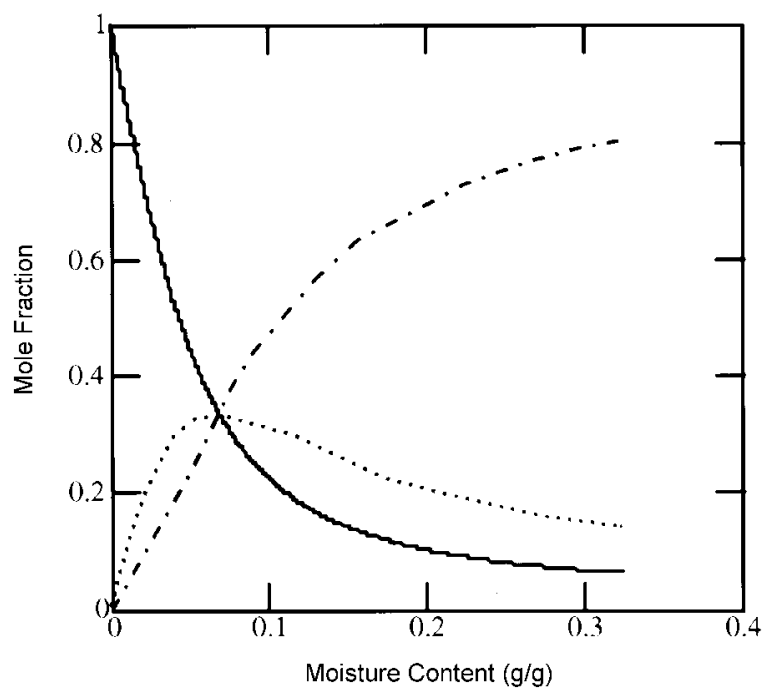

Figure 6.

Species distribution for bright tobacco as a function of moisture content. Solid line: unhydrated sites; dotted line: hydrated sites, dash-dot line: free water.

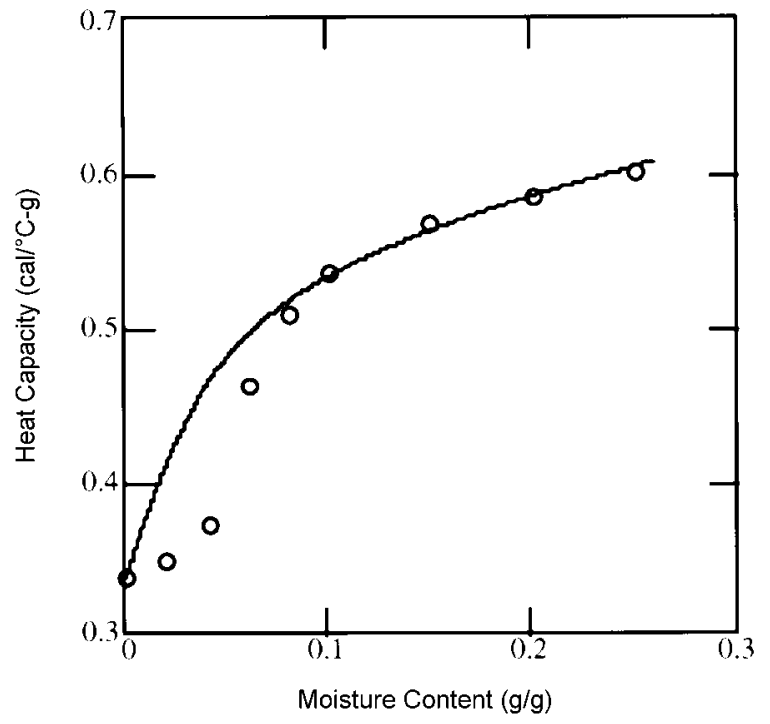

Figure 7.

Heat capacity of bright tobacco as a function of moisture content. Data points from reference 4. Solid line calculated from equation [17] with

$$
\bar{C}_{W S}=0.6 \mathrm{cal} /{ }^{\circ} \mathrm{Cg} \text {. }
$$

If the components of the solution interact, the $\Lambda$ 's are concentration dependent partial molar quantities defined as:

$$
\Lambda_{i}=\left(\frac{\partial L}{\partial n_{i}}\right)_{T, P, n_{i}}
$$

For extensive properties, which depend on the total material present, the mole fractions in equation [15a] are replaced by mole numbers:

$$
L=\Lambda_{W} n_{W}+\Lambda_{W S} n_{W S}+\Lambda_{S} n_{S}
$$

The mole numbers for free water and bound water or hydrated sites, in terms of moles per gram bone dry tobacco, are given by :

$$
n_{W}=S^{0} \frac{b}{1-b} \text { and } n_{W S}=S^{0} \frac{K h}{1+K b} .
$$

The mole number of unhydrated sites can be obtained from mass balance:

$$
n_{S}=S^{0}-n_{W S} .
$$

The mole fraction of each species can now be calculated via: 


$$
\begin{aligned}
& X_{W}=\frac{n_{W}}{n_{W}+n_{W S}+n_{S}} \\
& X_{W S}=\frac{n_{W S}}{n_{W}+n_{W S}+n_{S}} \\
& X_{S}=\frac{n_{S}}{n_{W}+n_{W S}+n_{S}} .
\end{aligned}
$$

The species distribution as a function of moisture content for bright tobacco is shown in Figure 6. The mole fraction of unhydrated sites decreases monotonically. The mole fraction of hydrated sites initially rises then falls off due to dilution by free water.

If the $\Lambda$ 's in equation [15] are constants, physical properties will vary with moisture content as linear combinations of the distribution curves shown in Figure 6.

\section{HEAT CAPACITY}

The data used in this analysis is taken from the determination by SAMFIELD and coworkers of the heat capacity of bright tobacco as a function of moisture content (5). Heat capacity is an extensive property and is thus best described by:

$$
C_{P}=n_{S} \bar{C}_{S}+n_{W S} \bar{C}_{W S}+n_{W} \bar{C}_{W}
$$

SAMFIELD and coworkers determined the heat capacity of bone dry bright tobacco to be $0.338 \mathrm{cal} /{ }^{\circ} \mathrm{C}$ g. The heat capacity of free water is assumed to be $1 \mathrm{cal} /{ }^{\circ} \mathrm{C} \mathrm{g}$, the same as that of bulk water. These are specific heats which must be multiplied by the molecular weights to convert them to molar heat capacity values for use in equation [16]. The molecular weight $M$ of the average site can be obtained from the relationship:

$$
M=\frac{1}{s^{0}} .
$$

The molecular weight of the average hydrated site is then given by $M+18$. Finally, the right hand side of the equation must then be divided by the total sample weight to yield a specific heat for the tobacco. If the bone dry tobacco weight is one gram, equation [16] becomes:

$$
C_{P}=\frac{0.338 M n_{S}+C_{W S}(M+18) n_{W S}+18 n_{W}}{1+m}
$$

where $m$, it will be recalled, is the decimal dry weight basis moisture content and $C_{W S}$ is the specific heat of the
Table 3.

Thermal diffusivity.

\begin{tabular}{l|c|c}
\hline Tobacco $^{\mathrm{a}}$ & Moisture content $^{\mathrm{b}}$ & $\begin{array}{c}\text { Thermal } \\
\text { diffusivity } \times 10^{3 \mathrm{c}}\end{array}$ \\
\hline Bright & 0.109 & 0.85 \\
Bright & 0.166 & 1.00 \\
Bright & 0.232 & 1.08 \\
Recon A & 0.104 & 0.90 \\
Recon A & 0.820 & 1.24 \\
Recon B & 0.099 & 0.83 \\
Recon B & 0.194 & 1.06 \\
\hline
\end{tabular}

${ }^{a}$ Recon $A$ is a cast leaf product, Recon $B$ is an extract and
recombine product
b $\mathrm{g} / \mathrm{g}$ wet weight basis
${ }^{\mathrm{c}} \mathrm{cm}^{2} / \mathrm{sec}$

hydrated sites.

The specific heat of the hydrated sites is the only unknown in equation [17]. The values of $n_{S}, n_{W S}$ and $n_{W}$ were calculated using the values of the isotherm parameters $K$ and $S^{0}$ obtained from the isotherm of SAMFIELD and coworkers for bright tobacco at $25^{\circ} \mathrm{C}$. Equation [17] gave a good fit to the heat capacity data with a constant value of $0.61 \mathrm{cal} /{ }^{\circ} \mathrm{C} \mathrm{g}$ for $C_{W S}$ at moisture contents above 8-9\%. At lower moisture contents the heat capacity goes through a sigmoidal change. Figure 7 shows the heat capacity data and the superimposed curve generated by equation [17] using the constant value of $0.6 \mathrm{cal} /{ }^{\circ} \mathrm{C} \mathrm{g}$ for $C_{W S}$.

The sigmoidal shape of the heat capacity change is suggestive of a second order transition. The magnitude of the heat capacity change, from $0.338 \mathrm{cal} /{ }^{\circ} \mathrm{C} \mathrm{g}$ for unhydrated sites to $0.61 \mathrm{cal} /{ }^{\circ} \mathrm{C} \mathrm{g}$, the final value for hydrated sites, is consistent with the large change in the mobility of the tobacco expected to result from a second order transition.

\section{THERMAL DIFFUSIVITY}

The thermal diffusivity of several tobaccos was determined as a function of moisture content over the range of $10-80 \%$ water, wet weight basis, as described in a previous section. (The moisture contents in this section are given on a wet weight basis because it is more convenient for graphing high moisture contents.) The results are listed in Table 3 . The values are a strong function of moisture content but quite insensitive to tobacco type. Since unhydrated sites fall off rapidly as the moisture increases above $10 \%$, only hydrated sites and free water 


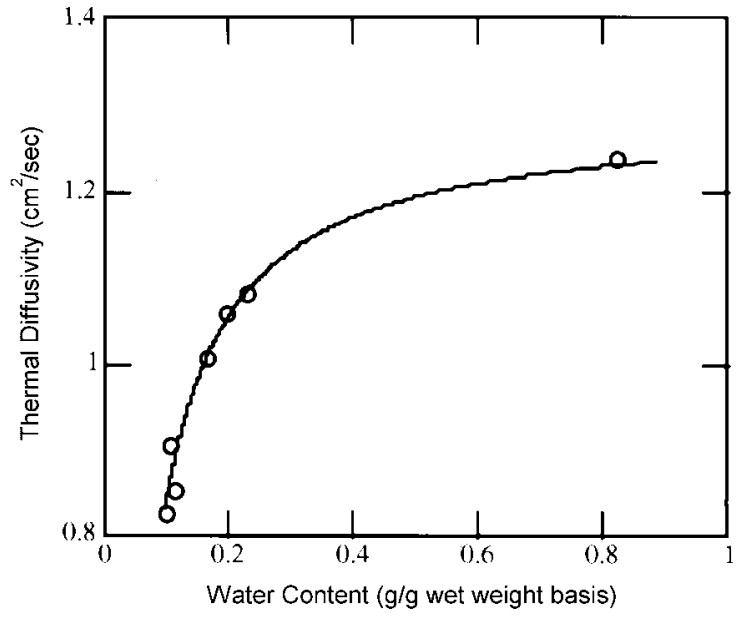

Figure 8.

Thermal diffusivity of tobacco as a function of moisture content (wet weight basis). Line calculated

from equation [19] with $\bar{D}_{W S}=7 \times 10^{-4} \mathrm{~cm}^{2} / \mathrm{sec}$.

are considered in this analysis. The relationship for thermal diffusivity is written:

$$
D=\bar{D}_{W S} X_{W S}+\bar{D}_{W} X_{W}
$$

The thermal diffusivity of bulk water at $25{ }^{\circ} \mathrm{C}$ was calculated to be $1.2 \times 10^{-3} \mathrm{~cm}^{2} / \mathrm{s}$ from reference sources. Insertion of this value into equation [18] yields:

$$
D=\bar{D}_{W S} X_{W S}+1.2 \times 10^{-3} X_{W}
$$

Since the data set pertains to bright and reconstituted tobaccos, values of $K$ and $S^{0}$ intermediate between those for bright and reconstituted tobacco were used in the calculations. Values of 4 and $3.8 \times 10^{-3}$ were used for $K$ and $S^{0}$, respectively. Equation [19] yielded a value of $7 \times 10^{-4}$ $\mathrm{cm}^{2} / \mathrm{s}$ for $\bar{D}_{W S}$. Figure 8 shows the curve generated by equation [19] with the experimental data superimposed. The agreement is excellent in this case.

The insensitivity of the thermal diffusivity to tobacco type can be explained both by the increasing dominance of free water as the relative humidity rises and the similar values of the water binding constants of the tobacco's involved.

\section{BROWNING REACTION}

The Browning Reaction is a complex sequence of reactions involving reducing sugars and ammonia or amine containing compounds such as amino acids and proteins. The results of the reaction in bright tobacco include a loss of reducing sugars, darkening of the color, loss of equilibrium moisture content and an increase filling power. The filling power increase is attributable to an increase in the modulus. The magnitude of the filling power increase was found to be a good indicator for the extent of the reaction.

The filling power increases, FP values, initial moisture contents and calculated initial relative humidities for bright tobacco samples subjected to heat treatment at $90^{\circ} \mathrm{C}$ for 48 hours are shown in Table 4 . The reactions in the tobacco were quenched by cooling after 48 hours. Since filling power is a good indicator for the extent of the reaction, the filling power increases at constant heat treatment time are a measure of the relative rates of reaction.

The Browning reaction has been studied in a variety of foods and agricultural materials $(15,16)$. The underlying chemical processes are complex and incompletely understood. The initial reaction is expected to be bimolecular. Nevertheless, the kinetics of associated changes such as the disappearance of reactants and the increase in brown color have been found to follow first order kinetics. It is very difficult to distinguish between first and second order kinetics for such processes. Water activity, which is equal to the decimal relative humidity $h$, has a marked influence affecting not only the concentration of the reactants but also on the activation energies and frequency factors of the apparent rate constants. These effects are only partially understood.

Studies of the effect of relative humidity have shown that the rates go through a maximum near $60 \% \mathrm{RH}$ or $b=$ 0.6. It is thought that at low relative humidities the low mobilities of the reactants retard the reaction. As the relative humidity rises the rate of reaction increases due to an increase in the frequency factor of the rate constant. This has been explained as a viscosity effect. The concentration of the reactants in the aqueous phase at low moisture content is probably at saturation and, therefore, constant. As the moisture rises the reactants

\section{Table 4.}

Heat treated bright tobacco.

\begin{tabular}{c|c|c}
\hline Moisture content $^{\mathrm{a}}$ & $\begin{array}{c}\text { Calculated } \\
\mathrm{RH}\end{array}$ & $\begin{array}{c}\text { Filling power } \\
\text { increase }\end{array}$ \\
\hline 0.047 & 0.23 & 6.1 \\
0.145 & 0.60 & 11.0 \\
0.200 & 0.69 & 11.0 \\
0.247 & 0.74 & 10.1 \\
0.383 & 0.83 & 6.2 \\
\hline
\end{tabular}

${ }^{a} \mathrm{~g} / \mathrm{g}$ wet weight basis 


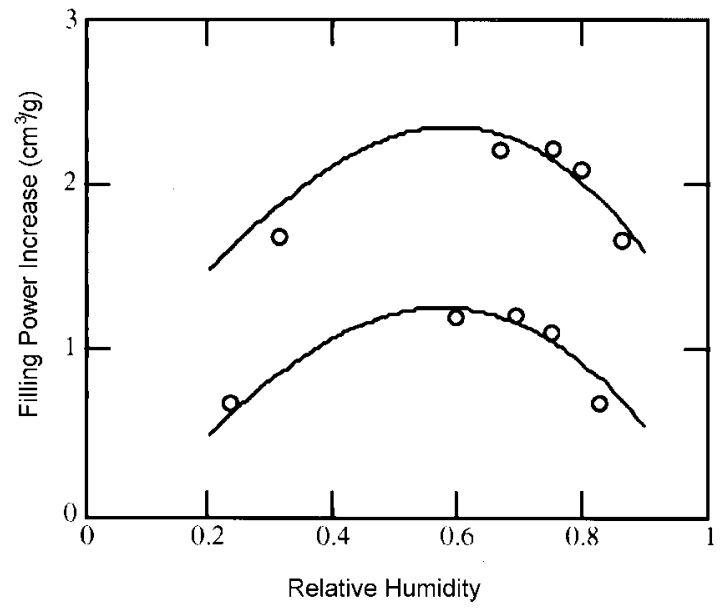

Figure 9.

Effect of relative humidity on the rate of the Browning reaction filling power increase is used as a measure of the extent of reaction. Lower curve refers to room temperature. Upper curve calculated for $60^{\circ} \mathrm{C}$. The upper curve was offset by 1.0 for clarity. Both curves were calculated using equation [20].

continue to dissolve. Eventually dissolution goes to completion and the concentrations declines due to dilution as moisture content continues to rise. The effect of the opposing tendencies is a peak in the rate near an $\mathrm{RH}$ of $60 \%$.

The opposing factors can be cast in terms of the species distributions of free water and hydrated sites. The mobility change at low humidity reflects a plasticization process which should parallel the free water concentration. The dilution at high humidity is apparent in the concentration of hydrated sites. The rate of the reaction should thus vary as the product of the mole fractions of hydrated sites and free water:

$$
\Delta F P=Q X_{W S} X_{W}
$$

where $Q$ is a proportionality constant.

The isotherm parameters listed for bright tobacco in Table 2 were used in testing equation [20]. The results of the calculations with $Q=8$ are shown by the lower curve in Figure 9. The tobacco data are superimposed. The curve peaks at $60 \% \mathrm{RH}$ and closely approximates the data.

Since the reaction was carried out at elevated temperature, a calculation was carried out to determine how temperature affects the match between the curve and the data points. The upper curve and data points, offset by 1.0 for clarity, were calculated at $60^{\circ} \mathrm{C}$ using the enthalpies derived from the data of SAMFIELD and coworkers in conjunction with the bright isotherm parameters in Table 2. The results show that the temperature increase shifts both the curve and the sample relative humidities by approximately the same amount maintaining the positions of the data points relative to the curve.

\section{MECHANICAL PROPERTIES}

Mobility and plasticization effects are expected to be functions of free water content. The model predicts that these will vary as the relative humidity. This is confirmed by the behavior of the filling power of bright tobacco shown in Figure 10. It should be noted that the line through the data in Figure 10 was obtained by regression and has no theoretical significance beyond confirming a linear relationship between filling power and relative humidity over the range of $60-75 \%$ relative humidity. As the relative humidity drops below $60 \%$, the second order transition seen with the heat capacity begins to strongly increase the modulus. This is, in all probability, the cause of the positive deviation from the line observed below $60 \% \mathrm{RH}$. The modulus is discussed further below. The linear decrease in filling power above $60 \% \mathrm{RH}$ is explained by the plasticization or softening of the tobacco shreds in the bed. However, this process has a limit. As the tobacco bed collapses, the bulk compressibility of the tobacco matrix starts to play an increasing role. This should result in another positive deviation at sufficiently high moisture.

However, the model was not successful in fitting the behavior of the modulus. Two related explanations can be offered:

1. The distribution represented by the equilibrium constant $K$ represents all water binding sites most of

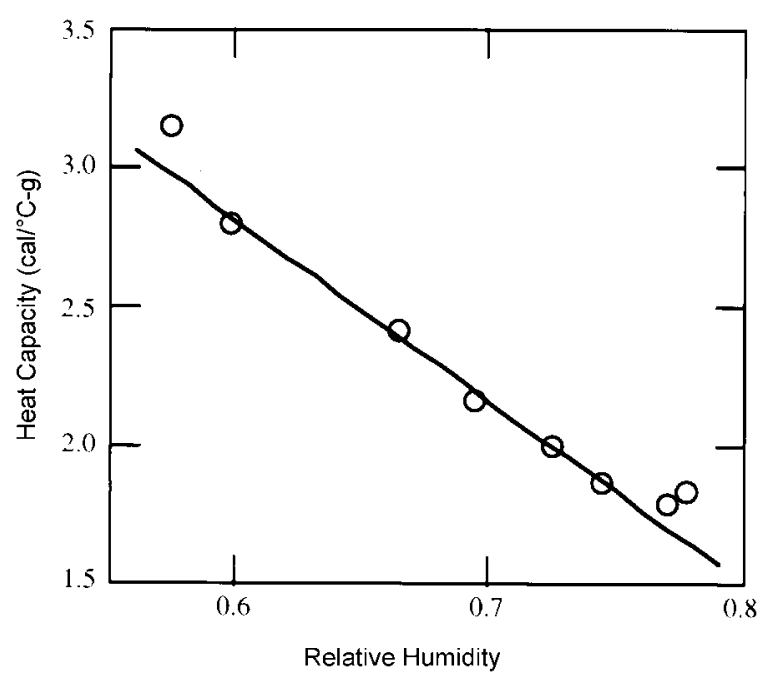

Figure 10.

Effect of relative humidity on filling power of bright

tobacco. The line was obtained by regression. 
which do not affect the modulus. The sites critical to the modulus are expected to be a small subset of the distribution.

2. The modulus should be dramatically affected by the second order transition noted above but the isotherm parameters are insensitive to it.

\section{DISCUSSION}

The model presented here for water sorption by tobacco is based in concept, though not in detail, on semi-ideal solution theory which has been applied with remarkable success to the activity coefficients of hydrophilic solutes such as sucrose and mannose (17-19). Semi-ideal solution theory assumes that all deviations from ideality are the result of the formation of hydrates by the solute. Water molecules that are not bound in a hydrate are presumed to be unaffected by the presence of the solute. Vapor pressure lowering is attributed to the reduction in the concentration of free water resulting from hydrate formation. The system is, thus, treated as an ideal solution comprised of water, solute and hydrated solute.

Each molecule is assumed to form hydrates by stepwise binding of water molecules. For the sake of simplicity, each water addition step is assumed to have the same equilibrium constant. Each solute molecule is a water binding site. Consequently the parameter $S^{0}$ is simply equal to the solute concentration.

Tobacco is more complex than a simple sugar solution. Not all sites are identical, their number is unknown and the hydration number is not necessarily the same for the different types of sites. Equation [12] was formulated to take into account different kinds of sites each with its own equilibrium constant. For the sake of simplicity it was assumed that each site can bind only one water molecule.

For a system with of a single kind of site, equation [12] reduces to equation [13]. It was found that tobacco isotherms fit equation [13] well over the $\mathrm{RH}$ range of $10-80 \%$. Given the diversity of potential water binding sites in tobacco, this raises the question of why tobacco obeys a simple single site isotherm equation. A plausible explanation is that the behavior of tobacco results from a distribution of sites rather than a single, specific type of site. Equation [12] very closely approximates equation [13] if the different kinds of water binding sites are symmetrically distributed with regard to their affinity for water. Equation [13] is, thus, a good model for the sorption isotherm of tobacco with the understanding that the equilibrium constant pertains not to any specific site but rather to the distribution average.

The activity coefficient of water in tobacco can be derived from the isotherm parameters. The activity of a component may have any numerical value depending upon the state chosen for reference. The selection of a reference or standard state is guided largely by convenience. On the basis of convenience, the binding sites of tobacco were treated as a solute and water as the solvent. The standard state is, thus, pure water and Raoult's law defines ideal behavior. Raoult's law for the vapor pressure of water over a solution is given by:

$$
P=P^{0} X_{\Sigma W}
$$

where $P$ is the vapor pressure of water above the solution, $P^{0}$ is the vapor pressure of pure water and $X_{\Sigma W}$ is overall mole fraction of water. The activity coefficient is defined as the actual vapor pressure divided by the vapor pressure the solution would have if it were ideal, i.e. obeyed Raoult's law:

$$
\gamma_{W}=\frac{P}{P^{0} X_{\Sigma W}}=\frac{b}{X_{\Sigma W}} .
$$

The ratio $P / P^{0}$ is the decimal relative humidity $h$. In computing $X_{\Sigma W}$ no distinction is made between bound and free water or between hydrated and unhydrated sites. $X_{\Sigma W}$ is defined as the total moles water over the total moles sites plus total moles water:

$$
X_{\Sigma W}=\frac{n_{W}+n_{W S}}{s^{0}+n_{W}+n_{W S}}=\frac{m}{18 S^{0}+m} .
$$

The total mole fraction water can be cast in terms of the isotherm parameters leading to the following expression for the activity coefficient:

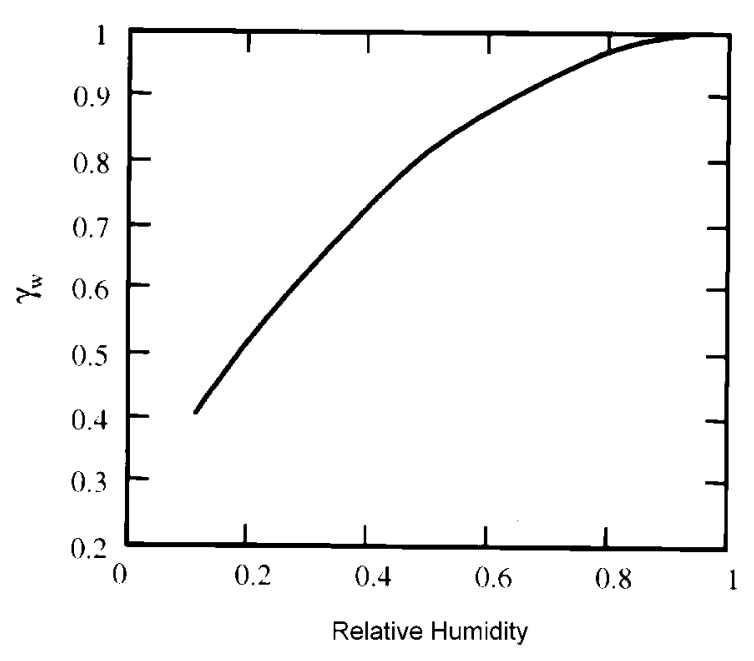

Figure 11.

The activity of coefficient of water in bright tobacco as calculated from equation [24] 


$$
\gamma_{W}=\frac{h\left(1+\frac{b}{1-b}+\frac{K b}{1+K h}\right)}{\frac{b}{1-b}+\frac{K b}{1+K b}}
$$

$S^{0}$ cancels out leaving the activity coefficient a function of $K$ and $h$ only.

In the absence of water binding, i.e. $K=0$, the right hand side of equation [24] reduces to unity, i.e. ideal behavior, in accordance with assumption 3 . Since water is defined as the standard state, the value of $\gamma_{W}$ be one for pure water, i.e. for $b=1$. Equation [24] fails to satisfy this condition since it exhibits a singularity at $h=1$. However, despite the singularity, the limit of $\gamma_{W}$ is one as $h$ approaches one:

$$
\lim _{h \rightarrow 1} \gamma_{W}=1
$$

Hence, equation [24] is well behaved as long as $h$ remains infinitesimally less than one.

The calculated value of $\gamma_{W}$ for bright tobacco is shown oven the RH range of 10 to $99.99 \%$ in Figure 11. The curve was extrapolated above the experimental range of 10 to $80 \% \mathrm{RH}$ to show its behavior as $h$ approaches unity.

With the activity coefficient in hand, equation [15] can be recast in terms of two components, water and tobacco:

$$
L=\Lambda_{T o b} X_{T o b}+\Lambda_{W} X_{\sum} \gamma_{W}
$$

Here tobacco is, in effect, treated as a solute with a molecular weight of $1 / S^{0}$. Equations [25] and [15] are equivalent. However, equation [15] is more useful for examining the effects of water on tobacco.

Though equation [14] and the BET equation are essentially identical in form, there is a difference in detail between the two models. Multi-layer water in the BET model and free water in the present model are not identical. Water beyond the first layer in the BET model is bulk water. Addition of further water molecules is simply a matter of condensation. In the solution model the addition of water molecules involves not only condensation but also mixing. The sorption process can conceptually be split into two steps. The first involves the mixing of water with unhydrated sites. The second step is the hydration reaction.

The model allows hydrate formation between water and sites but precludes any other interactions. Consequently the enthalpy of the first step is zero by definition. There is, however, an entropy associated with mixing. Since unhydrated tobacco sites and water are the only species involved, the entropy of mixing can be written:

$$
d S_{m i x}=-R\left(n_{T o b} \ln X_{T o b}+n_{\sum W} \ln X_{\Sigma W}\right)
$$

where $n_{T o b}$ is equal to $S^{0}$ and $n_{\Sigma W}$ is simply $\mathrm{m} / 18$. The mole fraction $X_{\Sigma W}$ has been defined above and $X_{T o b}$ is given by $1-X_{\Sigma W}$. Since the mole fractions are less than one, the entropy of mixing is positive despite the negative sign. The second step is the hydration of the sites. This is associated with both an enthalpy of hydration and an entropy of hydration. The overall entropy is, thus, the sum of the entropies of mixing and hydration. The overall enthalpy is equal to the enthalpy of hydration. The overall Gibbs free energy is given by:

$$
\Delta G=\Delta H-T \Delta S=\Delta H_{\text {byd }}-T \Delta S_{\text {byd }}-T \Delta S_{\text {mix }}
$$

or: $\Delta G=\Delta G_{\text {byd }}-T \Delta S_{\text {mix }}$.

The entropy of mixing was evaluated over the whole range of the isotherm and was found to contribute less than ten calories to the overall free energy which has a value of -600 calories. The entropy term can, consequently, be reasonably neglected with the result:

$$
\Delta G \cong \Delta G_{b y d} .
$$

It has been observed that the water sorption isotherm of tobacco at sufficiently high relative humidities becomes linear with $h /(1-b)(20)$. This behavior follows from equation [13]. The concentration of bound water rises rapidly at low relative humidity. However, as the relative humidity increases beyond approximately $50 \%$ further changes becomes very small. Bound water can be treated as constant at relative humidities above about $50 \%$. This leads to the following isotherm equation:

$$
m=185^{\circ}\left(\frac{b}{1-b}+\frac{K \bar{b}}{1+K \bar{b}}\right)
$$

where $\bar{b}$ is the average value of $h$ in the range above $50 \%$ $\mathrm{RH}$.

Equation [28] predicts that a graph of $m$ versus $h /(1-b)$ should yield a straight line with slope of $185^{\circ}$ and an intercept of:

$$
\text { int }=185^{\circ} \frac{K \bar{h}}{1+K \bar{h}} .
$$

Equation [28] was tested using the sorption data of SAMFIELD and coworkers for bright tobacco at $37.8^{\circ} \mathrm{C}$. This data set covers the RH range of 10 to $80 \% \mathrm{RH}$. The 


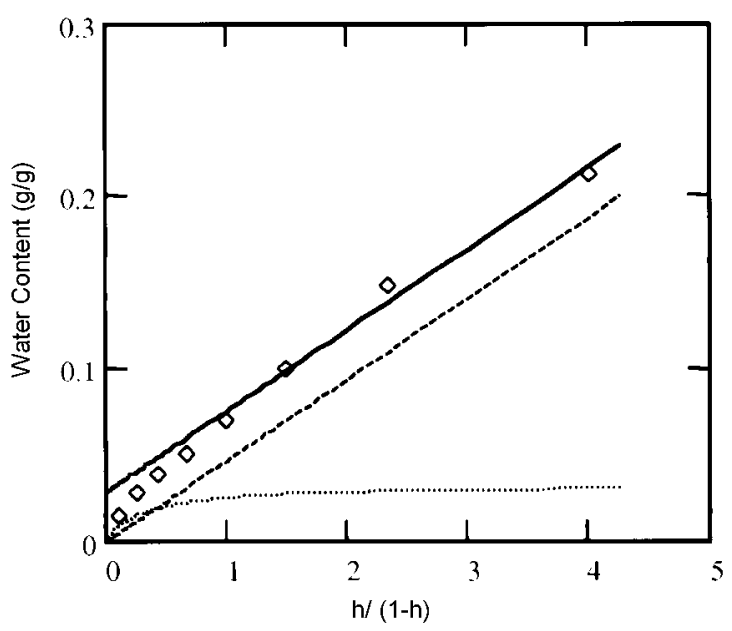

Figure 12.

Linearized isotherm for bright tobacco. Solid line is regression line for $\mathrm{RH} 50 \%$ and above. Dotted line shows calculated bound water. Dashed line shows calculated free water

range of essentially constant bound water is $50-80 \%$ $\mathrm{RH}$, hence, the value of $\bar{b}$ is 0.65 . Analysis of the isotherm yielded values of 2.4 and $2.6 \times 10^{-3}$ for $K$ and $S^{0}$, respectively. The predicted values calculated for the slope and intercept are 0.047 and 0.029 , respectively. Figure 12 shows the sorption data graphed against $h /(1-b)$. The solid line shows the regression line obtained using only the points at $50 \% \mathrm{RH}$ and greater. The regression analysis yielded values of 0.047 and 0.029 for the slope and intercept, respectively, with a correlation coefficient of 0.99 . The agreement with prediction is very close. The dotted line shows the calculated bound water and the dashed line represents the calculated free water. In the linear range the bound water is virtually constant. The increase in total water is the result of the rise in free water.

The results in Figure 12 demonstrate that isotherm models can be adequately tested only in the low $\mathrm{RH}$ range where bound water is significantly changing. Above that region any function that yields the required constant value, when combined with the free water term, will fit the sorption data.

The laws governing the behavior of solutions are sufficiently general to be obeyed in situations far removed from a true solution state. This is true to a surprising extent for tobacco. The behavior of tobacco with respect to water at moistures beyond the second order transition region approximates an ideal solution.

Both the heat capacity and the thermal diffusivity curves fit the data at relative humidities above the second order transition with constant $\Lambda$ values. The $\Lambda$ 's are partial molar quantities which, in general, are concentration dependent. However, in ideal solution they take on the meaning of molar quantities, e.g. the molar volume of water, which are constants. The isotherm data of SAMFIELD and coworkers show that the heat of desorption approaches the heat of vaporization of water for this moisture region which means that the heat of mixing approaches zero, another characteristic of ideal solutions. Apparently in this region the tight water binding sites have already been satisfied and the remaining sites interact sufficiently weakly with water for tobacco to approximate an ideal solution. It is reasonable to expect that other properties such as the specific volume or the diffusion coefficient of water will exhibit the same behavior.

The behavior in the transition region is markedly different. Here the assumption of constant $\Lambda$ values does not work as shown by the heat capacity data. The heat capacity of unhydrated sites cannot be affected by water, leaving $\bar{C}_{S}$ a constant. Free water is assumed to have the same properties of bulk water which fixes the value of $\bar{C}_{W}$ at the molar heat capacity of water. The concentration dependence must thus be attributed to $\bar{C}_{W S}$ the partial molar heat capacity of the hydrated matrix. The values of $\bar{C}_{W S}$ calculated from the data of SAMFIELD and coworkers via equation [17] are shown in Figure 13. The line through the data was generated by the function:

$$
\bar{C}_{W S}=0.48+0.13 \tanh (7.9(b-0.36)
$$

The transition is centered on $36 \% \mathrm{RH}$. The initial value of $\bar{C}_{W S}$ calculated from equation [29], $0.35 \mathrm{cal} /{ }^{\circ} \mathrm{C} \mathrm{g}$, is not significantly different from the value of 0.338 $\mathrm{cal} /{ }^{\circ} \mathrm{C} \mathrm{g}$ determined by SAMFIELD and coworkers for bone dry tobacco. The attachment of water to a site appears to have little effect on its heat capacity. The large

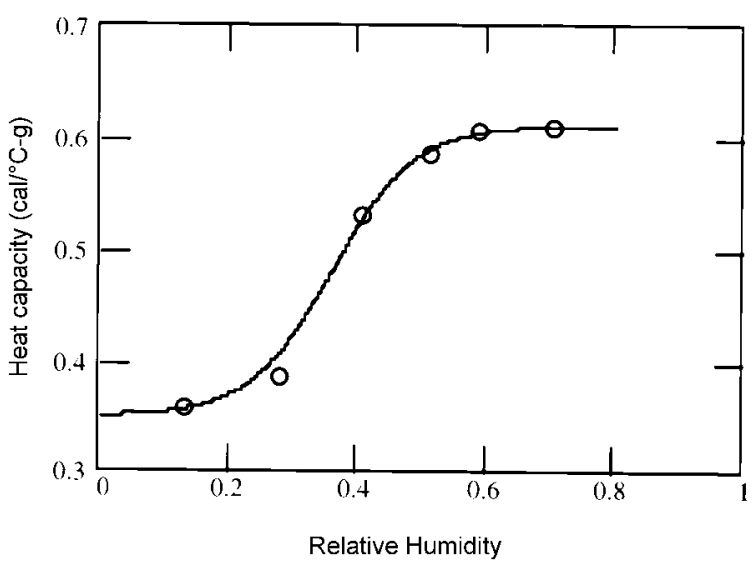

Figure 13.

The partial molar heat capacity of the hydrated tobacco matrix. The data points were calculated from reference 4 using equation [17]. The line was calculated from equation [21] 
change results from the subsequent transition.

The modulus of bright tobacco is also strongly affected by the transition. As the moisture content is reduced down to the transition region the stiffness and the friability of tobacco rise sharply. Figure 14 shows the dependence of the modulus of bright strip on relative humidity (21). The line through the data is given by:

$$
Y=198-195 \tanh (7.9(b-0.36) .
$$

The diffusion coefficient of water in tobacco should also be affected by the transition dropping sharply as the moisture is reduced below $8 \%$ and the tobacco enters the glassy state. This accounts for the observation that the rate of water desorption decreases markedly below 7-8 \% water content.

Taken together, the heat capacity and modulus data provide convincing evidence for the existence of a moisture driven second order transition in bright tobacco centered at about $36 \% \mathrm{RH}$.

There is no apparent correlation between the transition and coverage of the BET monolayer. The degree of hydration, or fractional monolayer coverage, $\theta$ is given by:

$$
\theta=\frac{K h}{1+K h}
$$

Figure 15 shows a graph of $\theta$ as a function of relative humidity for both bright and Burley tobacco. At $36 \%$ $\mathrm{RH}$ the value of $\theta$ is only 0.53 for bright tobacco. At $80 \% \mathrm{RH}, \theta$ reaches values of only 70 and $85 \%$ respectively for bright and Burley, respectively. Large values

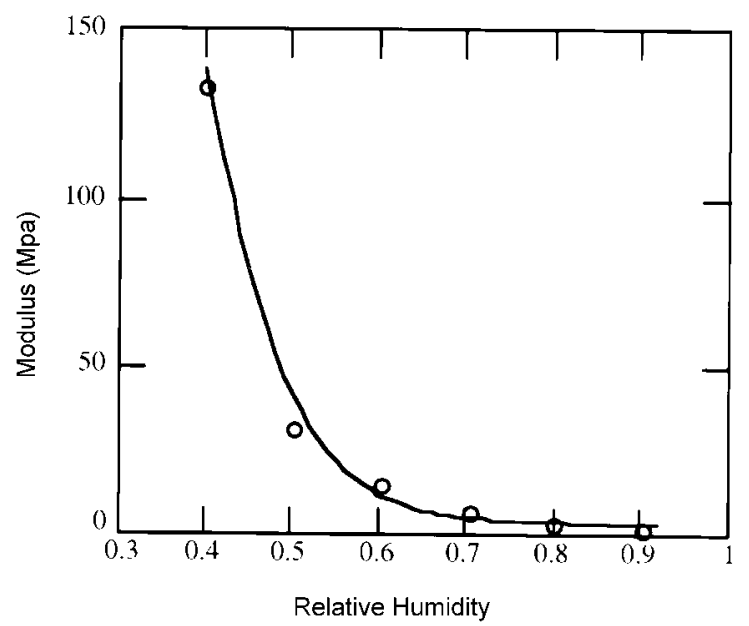

Figure 14.

The effect of relative humidity on the value of Young's modulus for bright tobacco. The data points are from reference 12. The line was generated using equation [22]. of $K$ are required to approach complete monolayer coverage at moderate or low moisture contents. For example a $K$ value of 270 is required to attain $99 \%$ coverage by the middle of the transition. The experimental value of $K$ determined for bright tobacco from sorption data is about two orders of magnitude smaller. It will be recalled that the value of $K$ in tobacco refers to the average of the distribution over all water binding sites. The transition, on the other hand, is initiated after some smaller number of critical sites are hydrated.

The isotherm equation is based on an equilibrium, i.e. reversible, water binding process. Consequently, the monolayer can, in principle, never be fully covered. The right side of equation [23] goes to unity only when the relative humidity approaches infinity.

The results of the Browning reaction shown in Figure 9 provide the most striking confirmation of the species distribution model. The shape of the curve derives from the isotherm parameters alone. The only adjustable parameter involved is the scaling factor $Q$ which shifts the curve up or down as a whole.

The curve reaches down to the low moisture region where the second order transition plays a role. This does not affect the curve which involves only the calculation of mole fractions. The transition has a strong impact on mobilities and should affect the rate data. However, such transitions in tobacco are driven by both moisture and temperature. Moisture effects dominate the transition at low temperature. The reaction was carried out at $90^{\circ} \mathrm{C}$ where the transition will go to completion even at low moistures and, thus, have no effect on the kinetics.

It remains to comment on the nature or definition of "bound" water. SEEHOFER (22) described three general types of bound water in tobacco: chemically bound water which includes ion-dipole and hydrogen bonded interactions, water bound by van der Waals forces, and capillary water. In context of the present model it seems appropriate to postulate bound water in terms of two categories: waters bound to discrete sites and waters of hydration or solvation.

Discrete sites include the inner coordination sphere of divalent metal ions. Waters in the inner coordination sphere are most frequently held in a octahedral array around the central metal ion. They are readily distinguishable from bulk water though they can easily exchange with it. A second category of distinct sites occurs in biopolymers (23). Since such sites have to compete with bulk water where as many as four hydrogen bonds are available, they are comprised of two or more functional groups arrayed in a configuration that permits the formation of multiple hydrogen bonds with a water molecule.

The remaining bound waters are involved in the hydration of solubles and hydrophilic sites on polymers. 


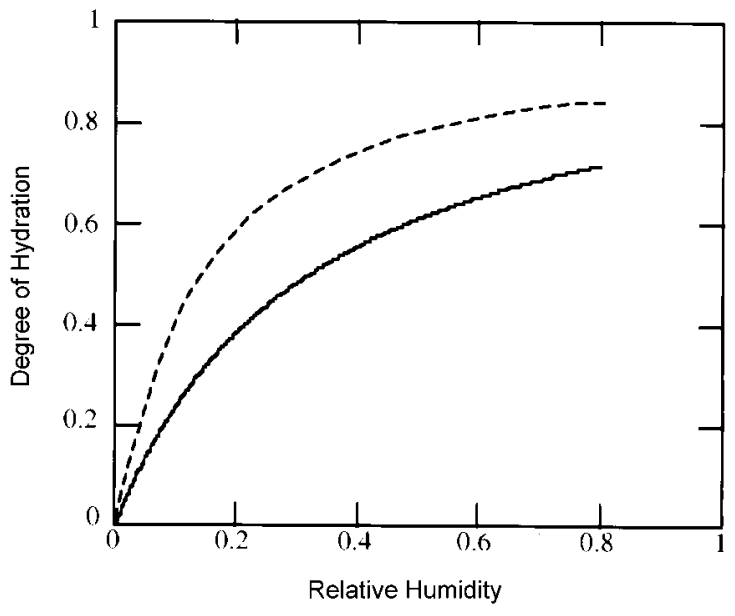

Figure 15.

The degree of hydration for bright (solid line) and Burley (dashed line) tobacco as a function of relative humidity. The lines were calculated using equation [23].

These effects are, most likely, loose associations between water and solutes or perturbations of solvent structure the net effect of which can be thermodynamically characterized as water "binding".

\section{REFERENCES}

1. Brunauer, S., P.H. Emmett and E. Teller: Adsorption of gases in multimolecular layers; J. Amer. Chem. Soc. 60 (1938) 309-319.

2. Hailwood, J. and S. Horrobin: Absorption of water by polymers: analysis in terms of a simple model; Discussions of the Faraday Society XLII B (1946) 84-101.

3. Carslaw, H.S. and J.C. Jaeger: Conduction of heat in solids, 2nd Edition; Clarendon Press, Oxford, 1995.

4. Saunders, D. J. and R. C. Forsyth: Measurement of thermal conductivity and contact resistance of paper and thin-film materials; Rev. Sci. Inst. 54 (1983) 238-244.

5. Brock, B.A. and M. Samfield: The heat capacity of tobacco - Part I; Tob. Sci. 2 (1958) 41-44.

6. CRC Handbook of Chemistry and Physics, $54^{\text {th }}$ Edition, edited by R. C. Weast, CRC Press, Cleveland, Ohio, 1973-1974, pp. F11, D137, E26.
7. Zorbalas, D. I.: Über die Wasserdesorption des Tabaks; Beitr. Tabakforsch. 4 (1968) 85-89.

8. Jadraque, D. and A. R. Mendiola: Specific surface area of tobacco adsorption measurements; Ann. du Tabac 23, Section 1 (1994-96) 3-14.

9. Barnes, H. M., C. Skaar and P. Luner: Water sorption by amylose and cellulose acetates; J. Appl. Polym. Sci. 21 (1977) 1085-1094.

10. Chang, C. S. and W. H. Johnson: The relationship between specific volume and specific surface area of tobacco; Tob. Sci. 17 (1973) 115-119

11. Brunauer, S., L. S. Deming, W.E. Deming and E. Teller: On a theory of the van der Waals adsorption of gases; J. Amer. Chem. Soc. 62 (1940) 1723-1732.

12. Zorbalas, D. I. : Bestimmung der Bindungswärme des Wassers im Tabak; Beitr. Tabakforsch. 4 (1968) 301-307.

13. Locklair, E. E., L. G. Veasey and M. Samfield: Equilibrium desorption of water vapor on tobacco; Agricult. Food Chem. 5 (1957) 294-298.

14. Pauling, L.: The adsorption of water by proteins; J. Amer. Chem. Soc. 61 (1945) 555-557.

15. Rockland, L. B. and S. K. Nishi: Influence of water activity on food product quality and stability; Food Technol. 34 (1980) 42-51.

16. Labuza, T.P.: The effect of water activity on reaction kinetics of food deterioration; Food Technol. 34 (1980) 36-41.

17. Scatchard G.: The hydration of sucrose in water solution as calculated from vapor-pressure measurements; J. Amer. Chem. Soc. 43 (1921) 2406-2418.

18. Robinson, R.A. and R.H. Stokes: Activity coefficients in aqueous solutions of sucrose, mannitol, and their mixtures; J. Phys. Chem. 65 (1961) 1954-1958.

19. Franks, F. and D.S. Reid: Thermodynamic properties; in: Water a comprehensive treatise, Vol. 2, edited by F. Franks, Plenum Press, New York and London, 1981, p 366.

20. Horler, J.W.: personal communication.

21. Ganeriwala, S. N., A. K. Basak, J. L. Banyasz and Z. Gibbs: The Effects of moisture and temperature on mechanical properties of tobacco leaf lamina; $48^{\text {th }}$ Tobacco Chemists' Research Conference Program, Greensboro, NC., Volume 48, 1994, pp 35-36.

22. Seehofer, F: Bindungszustände des Wassers im Tabak; Beitr. Tabakforsch. 1 (1961) 117-124.

23. Berendsen, H. J.C.: Specific interactions of water with biopolymers; in: Water a comprehensive treatise, Vol. 5, edited by F. Franks, Plenum Press, New York and London, 1981, pp 293-330. 